\title{
Clusters of Receptors in Cullured Muscle
}

from our Neurochemistry Correspondent

THE discovery of specific and relatively high affinity "labels" for acetylcholine $(\mathrm{ACh})$ receptors in toxins from the venoms of certain snakes has not only facilitated progress in attempts to isolate and characterize such receptors from membrane fragments, but also allowed their precise localization and assay in intact tissues. Sytkowski, Vogel and Nirenberg (Proc. US Nat. Acad. Sci., 70,270 ; 1973) now describe how the use of $\alpha$-bungarotoxin has led to the discovery of an unexpected distribution of binding sites in mammalian embryo skeletal muscle cells grown in culture.

Physiologically, the presence of $\mathrm{ACh}$ receptors on a cell membrane is detected by the observation of characteristic changes in the potential of the membrane during the application of minute quantities of $\mathrm{ACh}$ by iontophoresis. This technique has shown that, in adult skeletal muscle fibres, sensitivity to $\mathrm{ACh}$ is normally restricted to the small end-plate regions where contact is established with nerve endings. But if a muscle is deprived of its nerve supply it becomes responsive to $\mathrm{ACh}$ along the entire length of its surface. Conversely, if the motor nerve fibres are allowed to regenerate into a denervated muscle, the sensitive area shrinks progressively and becomes restricted to the junctional region. Similarly, foetal muscle fibres are uniformly sensitive to $\mathrm{ACh}$, but after birth there is a retraction of sensitivity, this occurring in parallel with the development of the characteristic end-plate structure.

The nature of the influence causing this restriction of chemosensitivity is controversial. Nerve endings seem to be implicated, and it was originally suggested that they release some chemical, loosely called a "trophic substance", but so far no such substance has been successfully identified. It is possible that $\mathrm{ACh}$ itself is involved, but recent experiments in which it was found that chronic electrical stimulation of denervated muscles was sufficient to prevent or reverse the usual extra-junctional hypersensitivity, without affecting the sensitivity at the end-plate, suggest that it is activity in muscle fibres themselves which is critical in restricting their distribution of ACh receptors (Jones and Vrbová, J. Physiol., 217, 67P ; 1971 ; Lømo and Rosenthal, J. Physiol., 221, 493 ; 1972).

Sytkowski et al. grew chick-embryo skeletal muscle cells in culture in the absence of neurones. Cultures of the dissociated myoblasts were incubated at various stages with ${ }^{125}$ I-labelled $\alpha$ bungarotoxin, and the distribution of bound toxin was determined by radioactive counting and by autoradiography. Dividing myoblasts bound very little toxin; after about 3 days the cells began to fuse, forming non-dividing multinucleate myotubes, and this phase was accompanied by a sharp rise in the amount of toxin bound until a plateau was reached on the eighth day of incubation. Autoradiography showed that in 5-day cultures, myotubes had a more or less uniform distribution of label, implying a uniform distribution of $\mathrm{ACh}$ receptors along the surface. After seven days, however, discrete clusters of binding sites, where the label was seen to be more concentrated than at adjacent regions, became apparent; by the eleventh day more than 80 per cent of the myotubes had such clusters. Individual myotubes had more than one cluster and some as many as twenty; the average cluster size was $125 \mu \mathrm{m}^{2}$. The concentration of binding sites at clusters was 9,000 per $\mu \mathrm{m}^{2}$, implying a density of cholinergic receptors similar to that reported for end-plates, whereas in other regions of the cell the apparent receptor concentration was 900 per $\mu \mathrm{m}^{2}$.

These results imply that some selectivity in the distribution of toxin-binding sites occurs in the absence of neurones, a process interpreted by the authors as a step in the formation of a functional synapse. This is of great interest in view of the finding that activity in muscle fibres may be sufficient to maintain the normal pattern of ACh-sensitivity. It would be worthwhile knowing if cluster formation coincides temporally with the onset of electrical changes and contractile activity in cultured muscle cells.

Sytkowski et al. are perhaps overhasty in equating $\alpha$-bungarotoxin binding sites with cholinergic receptors. Two reports have appeared of preparations which unexpectedly bound $\alpha$-bungarotoxin to a high degree, cie an axonplasma membrane fraction (Denburg, Eldefrawi and O'Brien, Proc. US Nat. Acad Sci., 69, 177 ; 1972), where there is no other pharmacological evidence for the presence of ACh receptors, and the other a homogenate of the cerebral cortex (Bosmann, J. Biol. Chem., 247, 130 ; 1972), where the binding capacity for $\alpha$-bungarotoxin far exceeded the number of sites receptive to $\mathrm{ACh}$ as estimated by iontophoretic application.

The findings from these preparations indicate either the presence of a modified $\mathrm{ACh}$ receptor, or that $\alpha$-bungarotoxin is not entirely specific to that receptor, and the same limitations may apply to the study of Sytkowski et al. Nevertheless Sytkowski et al. quote evidence of Cohen and Fishbach that discrete areas of high $\mathrm{ACh}$ sensitivity can be detected in cultured muscle cells electrophysiologically, and this would suggest that the toxin-binding sites do represent functional $\mathrm{ACh}$ receptors.

\section{PUBLIC HEALTH}

\section{WHO Reports on Hepatitis}

from a Correspondent

VIRAL hepatitis was recognized as a serious public health problem by the World Health Organization soon after its establishment (Wld Hlth Org. Tech. Rep. Ser., No. 62 ; 1953 ; and No. 285 ; 1964), but little progress in hepatitis was made until the discovery in 1968 of the association between hepatitis $B$ antigen and serum (type B) hepatitis. In 1970 an informal consultation on viral hepatitis was held in Geneva and a useful memorandum on the methods of testing for hepatitis B antigen and antibody was published (Bull. Wld Hlth Org., 42, 957; 1970).

Progress has continued unabated and another meeting was recently convened by the Director General of the World Health Organization. The report of this scientific group has just been published (Viral Hepatitis, Tech. Rep. Ser., No. 512; 1973).

The main body of the report deals with hepatitis $B$ and recent advances are emphasized throughout. The epidemiology of the infection in different geographical, ethnic and social groups is described and the methods for measuring hepatitis B antigen and antibody are considered. The table giving information on the sensitivity, feasibility, expenses and time required for completion of the tests in common use will prove most valuable for laboratory workers and also for administrators and government advisers who will have to finance the screening programmes. A method having the 